\title{
ALGUNS ASPECTOS DA INDIVIDUALIZAÇÃO DA PENA
}

\author{
Laertes M. Munhoz \\ Professor Catedrático da Universidade do \\ Paraná
}

1) A Constituição Federal de 1946 inscreveu no Capítulo dos direitos e garantias individuais o princípio da individualização da pena, determinando que "a lei penal regulará a individualização da pena" (art. $141 \S 29$ ).

Antes do advento desse preceito de ordem constitucional, o nosso Código Penal de 1940 havia estabelecido os rumos a seguir para a aplicação da pena, atribuindo á competência do Juiz a fixação da quantidade da pena aplicável, dentro dos limites legais. Para a fixação dessa quantidade caberá ao Juiz atender aos antecedentes e á personalidade do agente, à intensidade do dolo ou grau da culpa, aos motivos, ás circunstâncias e consequências do crime (art. 42).

Disso decorre, indiscutivelmente, que a fixação da quantidade da pena aplicável fica entregue a uma grande dose do arbítrio judicial.

Vale, assim, ressaltar que no Direito pátrio a individualizacão da pena tem um critério bifronte, baseado em princípios que se repelem: de um lado é direito e garantia individual; de outro lado é emanação do arbítrio do Juiz. São duas épocas que se defrontam num antagonismo de princípios e de estilos. Úma, representada pelo Código Penal de 1940, elaborado e promulgado sob a égide do chamado Estado Autoritário, acoimado de fascista. Outra, representada pela Constituição política de 
1946, documento de expressão reinvindicadora das liberdades públicas, oriundo do grande movimento restaurador do regime democrático.

O contraste é flagrante. Tudo está, porém, a indicar que o legislador constituinte de 1946 teve em vista um novo estatuto legal da individualização da pena, mediante o qual se pudessem resguardar, ao mesmo tempo, a santidade dos direitos individuais e os interêsses da defesa social. Por isso determinou que "a lei penal regulará a individualização da pena".

Resta agora que a êsse preceito de ordem constitucional, escrito no Capítulo dos direitos e garantias individuais, venha a lei a dar um regulamento consentâneo com a sua finalidade eminentemente democratica.

2) E irrecusável que a tendência mais acentuada do Direito Penal de hoje é no sentido da individualização da pena. Mas essa individualização não deve sujeitar-se aos cânones do chamado direito livre, em que se inspira o arbítrio judicial, tão do agrado dos regimes de força.

Conforme as sabias palavras do Professor Adolphe Prins, a Bastilha era a arbitrariedade, mas também era o modêlo mais antigo da sentença indeterminada, do que decorre que o arbítrio judicial é parente próximo do despotismo.

A antigo direito francês como o antigo direito germânico ou anglo-saxão, comenta o ilustre Mestre de Bruxelas, se caracterizavam pelo arbítrio e pela severidade. As penas eram multiplas e crueis. O Juiz tinha a liberdade de escolher a pena que julgasse mais oportuna, e a sua escolha dependia do seu capricho e da sua vontade, mais disso do que das circunstâncias cbjetivas do caso ou da situação subjetiva do culpado ("Science Pénale et Droit Positif", Livre V, § 1er.).

Entre os romanos, que não foram dos mais primorosos penalistas, o Juiz podia castigar ad exemplum legis. Na Idade Média, o Juiz extraia as normas penais de sua própria conciência jurídica. (Talvez venha daí a Gesunde Volksanschauung do direito nazista). 
Originou-se de todo êsse passado de crueldades, a reação contra o arbítrio dos juizes, a qual encontrou em Beccaria um dos seus primeiros arautos e na Declaração dos Direitos do Homem a sua consagração revolucionária.

Mas daí surgiria um polo oposto de injustiças, das quais o classicismo penal não poderia afastar o seu sistema, baseado no combate à indeterminação da pena, para se ater à fixação legal da pena dentro de graus predeterminados. Dentro desse critério de normas igualitarias, impossível se tornava a individualização, com o que, sem sombra de dúvida, se agravariam as injustiças tão exploradas pelos corifeus da escola positiva nc seu ataque frontal contra a denominada equação penal.

$\mathrm{E}$ por que essa reação do positivismo de Ferri está, realmente, impregnada dos mais puros balsamos humanisticos, a individualização da pena passou a ganhar foros de cidade como princípios fundamentais da ciência penal contemporânea. $\mathrm{E}$ com isso renasce, como a hidra de Lerna, o problema do arbítrio judicial.

É, por isso mesmo, a individualização penal uma "arme á double tranchant", como bem observa Donnedieu de Vabres, quando diz: "Si l' arbitraire du juge, si l'individualisation de la peine, au contact des idées et moeurs démocratiques, ont milité pour l'adoucissement, pour l'humanisation de la justice pénale, nous les verrons, dans le climat des Etats autoritaires, produire des effets bien différents" ("La Crise Moderne du Droit Pénal", pág. 19).

A justiça autoritária jamais entendeu a lição de Tarde prefaciando Saleilles: "Plus fait douceur que violence", sem dúvida o grande lema da individualização, que esta sempre dependerá mais do juiz do que da lei. Perante a lei todos são iguais, mas o conceito de justiça como significação de igualdade, segundo a concepção aristotelica de Santo Tomás de Aquino, não pode desprezar a dissemelhança dos indivíduos.

Disso decorre que a individualização não pode ser feita a priori, pela lei. Só o contato judiciário poderá conhecer os desiguais para tratá-los num plano de igualdade. Aí é que sur- 
ge a missão do juiz, a qual, contudo, não se pode exaurir, uma vez fixada a quantidade da pena, devendo, pelo contrário, estender-se em todo o curso da sua execução, através da qual se irá fazendo a chamada individualização administrativa, fase culminante do processo da individualização, pelo melhor conhecimento, que proporciona, da personalidade do delinquente.

Diante, pois, da reconhecida inevitabilidade do arbítrio judicial em assunto de tal monta, o qual tão estreitamente se liga à liberdade individual, impõem-se, mais do que uma lei reguladora da individualização, a tarefa mais profunda da escolha e do preparo dos juizes. O trabalho de formá-los capazes de descerrar, com sabedoria e dignidade, "o manto que ocultá o sentido da lei".

3) Pelo que tudo indica, a lei não quer fazer da individualização um processo de exasperação contra a liberdade do indivíduo, embora delinquente; pelo contrário, uma garantia de que o sacrifício dessa liberdade não irá além do que fôr estritamente necessário para o bem da sociedade e do próprio indivíduo.

Encarada a matéria sob êsse prisma, poder-se-á compreender a inserção da individualização da pena no Capítulo que consagra os direitos e garantias individuais, quando tudo era de levar a crer que ao se estabelecerem êsses direitos e garantias, repelida estaria a idéia de se aceitar um instituto jurídico em que predomina o arbítrio.

É, de resto, o que observa o espírito liberal do Professor Jiménez de Asúa: "al establecerse las garantias individuales se cierra el acceso a la individualization penal"... ("Tratado", II, pág. 376).

0 problema da interpretação das leis penais, conforme assinala o grande Mestre de Madrid, põe frente a frente as duas grandes idéias que dominam o Direito Penal, a saber: a idéia do respeito à liberdade individual e a idéia da necessidade da defesa social. Deve-se tratar de resolver êste conflito, diz Asúa, "salvaguardando a la vez una y otra"... (obr. e pág. citadas). 
Para a solução desse conflito preconiza o Mestre, como ponto fundamental de partida, a formação de juizes responsáveis, bem retribuidos, independentes e com bastante preparaç̃̃o especializada não só em Direito, senão também em Criminologia, mais nesta, talvez, do que naquele, pois que, para êle, a Criminologia é uma ciência que acabará absorvendo o Direito Penal. Seja ou não seja a Criminologia uma ciência, o certo é que se impõe aos juizes criminais perfeito conhecimento dela. Não deve o juiz ser um simples ledor do texto do Código. $\dot{\mathrm{E}}$ de mister que penetre os meandros das ciências penais entre as quais a Criminologia, como entidade científica autonoma ou não, mesmo como preciência ou pseudo ciência, que domine a Antropologia, a Biologia e a Psicologia criminais. E a par disso ainda é de se exigir do juiz um sentimento cristão de humanidade aliado a um espírito cívico aprimorado.

Do contrário, a individualizacão da pena resvalará, senão para a tirania, ao menos para essa rotina de amanuense tão comum na maioria das sentenças em que, com certa displicência, chegam certos magistrados, sem saber bem por que, à fixação de uma denominada pena base, obtida sem qualquer base científica. É desolador verificar, na síntese apressada de muitas decisões, expressões como estas: "o dolo não foi intenso", ou "o dolo foi muito intenso", ou "o dolo foi normal", e assim por diante, no uso de verdadeiros chavões sem maior consistência lógica.

Deixa-se, via de regra, ao largo, o estudo da personalidade do agente, contentando-se alguns julgados, quanto a êste importantissimo problema, com o exame de um boletim de antecedentes fornecido pela autoridade policial. E a isso, geralmente, se resume o estudo da personalidade, que é, indiscutivelmente, um dos pontos mais sérios da individualização da pena.

E para o estudo da personalidade, como diz Frei Agostinho Gemelli, "bisogna fare la clinica del delitto", vale dizer, a reconstrução do processo mediante o qual chegou alguém a uma ação criminosa. É a reconstrução daquilo que Gemelli denomina a "genesipsicologia del delitto". 
Necessário, de conseguinte, que a lei reguladora da individualização da pena trace o método adequado para essa reconstituição psicológica do crime, problema que, evidentemente, não é dos mais fáceis nem pode ser encarado com o elementarismo com que alhures é êle tratado.

Dá-nos Gemelli a orientação a seguir, traçando um critério tríplice: a) somatico; b) psicofisiológico; c) psiquico. E em relacão a cada um expõe o que deve ser investigado, como por exemplo, no exame biológico: o tributo hereditário; as causas patológicas que possam ter influído durante a vida intrauterina, ou durante o parto; as doenças pregressas, etc.; no exame psicofisiológico deve-se recolher os dados relativos à acuidade sensorial, sua deficiencia ou anomalia; a reação da vida afetiva e a determinação dos seus correlativos psicológicos etc.; no exame psicológico: o estudo da atenção, da percepção; vínculos associativos; estados afetivos, etc. E ainda assim "quando tutti questi dati si sono raccolti in una cartella clinica si é fatto meno che niente e siamo ben lungi dall'essere arrivati alla diagnosi della personalità" ("La Personalità del Delinquente Nei Suoi Fondamenti Biologici e Psicologici" - Seconda Edizione, pág. 165).

Não será, portanto, com duas penadas bisonhas que se há de atender, no complexo problema da aplicação da pena, ao imperativo legal e indispensável do estudo da personalidade do agente. $\mathrm{O}$ exame da pessoa do delinquente é como a essência da própria individualização, e de tal maneira deve operar na fixação da quantidade da pena, que o próprio fato delituoso, nas suas circunstâncias objetivas, fica relegado a um plano inferior.0 elemento material da infração pode, muitas vêzes, conduzir a resultados errados de interpretação, por dar a impressão de uma periculosidade meramente aparente. Mais interessa pesquizar a gravidade subjetiva do crime.

4) Seguindo o modêlo do Código italiano de 1930, o Código brasileiro de 1940 também estabelece, entre as circunstâncias subjetivas a serem consideradas na aplicação da pena, a intensidade do dolo ou o grau da culpa. Mas o diploma italiano 
foi mais explicito do que o nosso. Aquêle define com clareza as circunstâncias objetivas e as circunstâncias subjetivas. (art. $70,1 .^{\circ}$ e $\left.2 .^{\circ}\right)$. 0 nosso, sem distinguir, engloba-as, genèricamente, na mesma disposição legal (art. 42) para, depois, estabelecer que no concurso de agravantes e atenuantes, a pena deve aproximar-se do limite indicado pelas circunstâncias preponderantes, entendendo-se como tais as que resultam dos motivos determinantes do crime, da personalidade do agente e da reincidência (art. 49). Para o caso da reincidência especifica determina que a pena privativa da liberdade seja aplicada acima da metade da soma do mínimo com o máximo, isto é, acima do grau médio (art. 47).

Nem aí se cuidou de regular um sistema tendente a diminuir a intervenção do arbítrio judicial. Mais feliz foi o Código peninsular facista, o qual inclui o tratamento da reincidência em Capítulo especial sob a epígrafe: "Da reincidência, da habitualidade e do profisisionalismo no crime e da tendência em delinquir", estabelecendo para a reincidência genérica um aumento até um sexto da pena a ser imposta pelo novo crime (art. 99) e um aumento até metade para reincidência específica (art. 99, $1 .^{\circ}$ ).

Igualmente, quanto às demais circunstâncias, quer atenuantes quer agravantes, o Código de Mussolin detém o arbítrio judicial dentro de limites certos, v. g. quando ocorre uma circunstância agravante, e o aumento da pena não está determinado em lei, aumenta-se até um terço a pena que deveria ser imposta (art. 64) e no caso de ocorrer circunstância atenuante, não prevista como caso especial de diminuição, a pena será diminuida em medida não excedente de um terço (art. 65).

Não é aqui de se examinar se na prática êsse critério tornará mais ou menos rigorosa a pena a aplicar, pois que o que vale é ressaltar a coibição que o sistema italiano põe ao arbítrio judicial.

Tudo dependerá, nos casos concretos, do maior ou menor espírito de liberalidade do juiz, pois quando êste está autorizado por lei a diminuir a pena de quantidade não excedente de 
um terço, em face da ocorrência de uma atenuante, só em hipótese muito especial deixará de usar dessa faculdade legal em tôda a extensão do seu limite.

Dentro, porém, do critério de nosso Código os casos de injustiça podem ser mais repetidos. Em hipótese de homicidio qualificado, o juiz, bem ou mal, fixa a chamada pena base em 20 anos de reclusão, mas como ocorre uma circunstância atenuante não prevista como causa especial de diminuição, reduz a pena de quatro anos, para chegar a uma condenação de 16 anos. Pelo Código italiano o juiz estaria autorizado a levar essa diminuição até um terço da pena fixada como pena base e concluir por uma condenação de 13 anos e seis meses. Também isso poderia acontecer em face da lei brasileira, porém de um modo inteiramente arbitrário. $\mathrm{E}$ assim como a condenação foi fixada em 16 anos, também poderia ser em 12 ou 19 ou em qualquer quantidade compreendida entre o mínimo de 12 anos e a base fixada em 20 anos.

São indiscutíveis as dificuldades com que há de se defrontar o aplicador da pena, quando tratar de medir a intensidade do dolo ou o grau da culpa.

Para o insigne Costa e Silva, "a intensidade do dolo significa o maior ou menor grau de conciência e voluntariedade dả ação delituosa" (Código Penal (publicação postuma) vol. I, pág. 243). Perfeitamente, mas como bem observa Ortolan "les elements qui font en plus ou en moins les milles nuances de la culpabilité sont multiples et se trouvent répandus dans tous les éléments et dans toutes les circonstances du délit". ("Elements de Droit Pénal," Paris, 1855, pág. 217).

A seguir, registra Ortolan a necessidade de se distinguir a culpabilidade abstrata ou absoluta da culpabilidade relativa ou individual: a primeira atinente ao delito de forma geral e a segunda concernente ao agente num determinado delito. $\mathbf{E}$ a lei penal, segundo diz o velho Mestre de Paris, não pode prever senão a culpabilidade abstrata ou absoluta, pois que a culpabilidade relativa ou individual cabe ao juiz apreciá-la em cada caso. 
Diante de tal lição caem por terra, como critério individualizador, as classificações mais ou menos artificiais do dolo, não podendo, por isso, prevalecer a simples invocação doutrinária dessas classificações. Todos sabemos que o dolo pode ser de impeto, premeditado, pode resultar de uma paixão cega ou de um cálculo frio. Não estará nisso, todavia, um critério certo para medida de sua intensidade, pois que não se poderá negar que, muitas vêzes, o dolo de impeto poderá revelar uma personalidade muito mais perigosa do que o dolo premeditado.

Impõem-se, dess'arte, que diante daquelas mil nuances de que se pode revestir a culpabilidade, tenha o juiz a acuidade, a sabedoria, a probidade que o habilitem a avaliar, de forma mais humana do que legal, o maior ou menor grau de conciência e voluntariedade da ação delituosa.

Até se notam algumas vêzes certas confusões entre intensidade do dolo ou grau da culpa. Há, evidentemente, duas modalidades da culpa, perfeitamente distintas: a culpa em sentido amplo e a culpa em sentido estricto. A culpa, no sentido amplo do direito punitivo, segundo a clássica definição de Kolrauch, traduzida por Costa e Silva "é aquela relação subsjetiva em que um individuo capaz de imputação se deve ter achado com o fato que praticou para por êle poder ser criminalmente responsável" (Irrthum und Schuld begriff, I - apud Costa e Silva, Código Penal dos Estados Unidos do Brasil, 1930, pág. 138). A culpa em sentido estrito é representada em nossa lei vigente, pela negligência, imprudência ou imperícia. É, com tôda a certeza, nêste último sentido que a menciona o artigo 42 do atual Código brasileiro, até porque se assim não fôsse teria incorrido numa incongruência imperdoável. Nem se poderia compreender que a culpa lato sensu fôsse coisa diferente do dolo.

Temos, desta forma, que o legislador cuidou também da individualização da pena nos crimes culposos, ao mencionar a expressão "grau da culpa". Não é fácil, porém, "atinar com o sentido atribuído a essa locução", como observa o douto Costa e Silva, para quem "não colhe perante o nosso direito a explicação dos criminalistas italianos, segundo os quais o maior 
cu menor grau da culpa se avalia pela maior ou menor previsibilidade do evento, pois que o Código pátrio, conforme a interpretação autêntica de Costa e Silva, "não aderiu à idéia da maior gravidade da culpa com previsão". Bem acentua, pois, Jorge Severiano que "também quanto à culpa, a lei aqui não merece louvores", referindo-se ao artigo 42 do atual Código (Código Penal dos Estados Unídos do Brasil, II, 148).

Mas, em verdade, desde os romanos, que a culpa pode ser consdierada grave, leve e levissima. Como, porém, avaliar êsses graus em face do nosso Direito? A tripartição romana era, dc resto, de natureza civilistica, critério que, como assinala Eusébio Gomez, já não subsiste na doutrina do Direito Penal $\epsilon$ tende a desaparecer completamente da legislação positiva, pois que a maior ou menor gravidade da culpa não pode ser clecidida a priori e sua apreciação deve ficar livre ao critério judicial (“Tratado de Derecho Penal”, I, pág. 209).

De nossa parte, já haviamos sustentado em nossa dissertação de 1943, que o critério para a apreciação da maior ou menor gravidade da culpa deve assentar na possibilidade ou impossibilidade de prever o resultado, para concluír que só o exame do caso concreto é que pode revelar a maior ou menor gravidade da culpa, conferindo-se, dess'arte, ao juiz uma grande dose de arbítrio ("Da Causalidade Subjetiva no Código Penal Brasileiro" pgs. 50 e 51).

Daí resulta mais uma vez a necessidade da presença de juizes aptos e cultos, verdadeiramente capazes de emprestar à individualização da pena o seu sentido constitucional como um dos parágrafos dos direitos e garantias individuais. É, todavia, comum a preguiça revelada na maioria das sentenças condenatórias, as quais, via de regra, são laconicas e apressadas. Com meia dúzia de palavras é geralmente fixada a denominada pena base, consistindo quase sempre essas palavras mera repetição, muitas vêzes até incompleta e outras vêzes errada, do próprio texto da lei. Sentenças há que mencionam ao mesmo tempo a intensidade do dolo e o grau da culpa, depois de se referirem "às consequências graves do crime" sem sequer especificá-las e justificá-las. 